\title{
MicroRNA-365 regulates the occurrence and immune response of sepsis following multiple trauma via interleukin-6
}

\author{
HUI GONG, XIAOMIN SHENG, JIANHUA XUE and DONGBO ZHU \\ Department of Emergency Surgery, Affiliated Hospital of Nantong University, Nantong, Jiangsu 226001, P.R. China
}

Received April 30, 2017; Accepted August 10, 2017

DOI: $10.3892 /$ etm.2018.6647

\begin{abstract}
In the present study, the expression of microRNA (miR)-365 and interleukin (IL)-6 in peripheral blood mononuclear cells and serum from patients with sepsis following multiple trauma has been investigated. A total of 26 patients with sepsis following multiple trauma were included as the experimental group, whereas 21 contemporaneous patients without sepsis following multiple trauma were included as the negative control group. The expression of IL-6 mRNA and miR-365 was determined by reverse transcription-quantitative polymerase chain reaction, and western blot analysis was used to measure IL-6 protein expression. ELISA was performed to determine the secretion of IL-6 protein. Following stimulation with lipopolysaccharide (LPS) for $24 \mathrm{~h}$, THP-1 cells were used to examine the expression of miR-365 and the levels of IL-6 protein and mRNA in cells simulating sepsis. A dual luciferase reporter assay revealed that IL-6 mRNA was a direct target of miR-365. Patients with sepsis following multiple trauma exhibited significantly higher IL- $6 \mathrm{mRNA}$ and protein levels than patients without sepsis $(\mathrm{P}<0.05)$. In addition, miR-365 expression in patients with sepsis following trauma was significantly lower than in patients without sepsis $(\mathrm{P}<0.05)$. Similar effects were observed in THP-1 cells treated with LPS. The present study demonstrated that increased expression of IL-6 in patients with sepsis following multiple trauma is associated with decreased expression of miR-365. miR-365 may regulate the occurrence and immune response of sepsis following multiple trauma via IL-6. These results may elucidate agents for clinical diagnosis and treatment of the disease.
\end{abstract}

\section{Introduction}

Multiple trauma is defined as the simultaneous injury of two or more anatomical sites of the body (1). Multiple trauma is often

Correspondence to: Dr Dongbo Zhu, Department of Emergency Surgery, Affiliated Hospital of Nantong University, 20 Xisi Road, Nantong, Jiangsu 226001, P.R. China

E-mail: zhudongbo77@126.com

Key words: microRNA-365, sepsis following multiple trauma, interleukin-6, mononuclear cells accompanied by major bleeding, shock or severe physiological disorders, all of which can be life threatening (1). Patients with multiple trauma typically exhibit systemic inflammatory response syndrome, sepsis or multiple organ dysfunction syndrome (2). Sepsis is a common complication of severe trauma, burns, shock and major surgery, and one of the main causes of mortality in patients with multiple trauma injuries $(2,3)$.

Sepsis is a serious complication of infection with a number of clinical manifestations and symptoms. Sepsis occurs when there is excessive inflammation in response to an infection, which subsequently damages the host (4). It is commonly accepted that the activation of neutrophils, lymphocytes and mononuclear macrophages and the release of endogenous mediators serve key roles in the pathophysiology of sepsis following trauma $(5,6)$. In 1992, sepsis was defined by the American Thoracic Society and the Society of Critical Care Medicine as an infection and systemic inflammatory response syndrome (7). Sepsis manifests as a systemic inflammatory response syndrome caused by infection, which requires rapid treatment (8).

Interleukin (IL)-6 is an important factor in immune responses that is produced by activated monocytes and macrophages (9). IL-6 promotes the growth and differentiation of primary bone marrow-derived cells by coordinating with colony stimulating factor, and enhances the lysing ability of natural killer cells (10-12). A previous study has reported that microRNA (miRNA or miR)-365 has a negative regulatory effect on IL-6 expression in 293 and HeLa cells (13). However, the regulatory effect of miR-365 on IL-6 in blood monocytes from patients with sepsis following multiple traumas is rarely reported. In the present study, miR-365 expression was measured, as well as the levels of IL-6 mRNA and protein in peripheral blood mononuclear cells (PBMC) and serum from patients with sepsis following multiple trauma, and the mechanism of action of miR-365 in sepsis was investigated.

\section{Patients and methods}

Patients. A total of 26 patients with sepsis following multiple trauma who received treatment at the Affiliated Hospital of Nantong University (Nantong, China) between June 2012 and January 2017 were included in the present study as the experimental sepsis group. During the same time period 21 patients without sepsis following multiple trauma were recruited as the negative control (NC) group. Among the patients with sepsis, 
11 were male and 15 were female (age range, 18-60 years; median age, 41 years). In the control group, 8 patients were male and 13 were female (age range, 16-62 years; median age, 42 years). None of the participants had diabetes, tumors or other immune diseases. The Ethics Committee of Nantong University approved all procedures and written informed consent was obtained from all patients or their families prior to their inclusion in the present study.

Peripheral blood was collected from all participants and stored at $4^{\circ} \mathrm{C}$ for $1-2 \mathrm{~h}$. The serum was then separated, centrifuged at a speed of $400 \mathrm{x} \mathrm{g}$ for $10 \mathrm{~min}$ at $4^{\circ} \mathrm{C}$, and aliquoted into Eppendorf tubes (100 $\mu 1$ in each tube) prior to storage at $-70^{\circ} \mathrm{C}$. To collect PBMCs, anticoagulant venous blood was mixed with an equal volume of serum-free Iscove's Modified Dulbecco's Medium (cat. no. 12440053; Thermo Fisher Scientific, Inc., Waltham, MA, USA) and the mixture was added onto the surface of human lymphocyte separation solution (5 ml; cat. no. 40503ES60; Shanghai Yeasen Biotechnology Co., Ltd., Shanghai, China). Following centrifugation at $400 \mathrm{x} \mathrm{g}$ for $30 \mathrm{~min}$ at $4^{\circ} \mathrm{C}$ the middle mist layer was gently aspirated into tubes and mixed with $5 \mathrm{x}$ the volume of Hank's balanced salt solution (cat. no. C0218; Beyotime Institute of Biotechnology, Haimen, China), the mixture then underwent centrifugation at $300 \mathrm{xg}$ for $10 \mathrm{~min}$. The cells were washed with Hank's balanced salt solution twice, and then diluted to $3 \times 10^{6}$ cells $/ \mathrm{ml}$ and seeded into culture dishes. Following cultivation at $37^{\circ} \mathrm{C}$ in an atmosphere of $5 \% \mathrm{CO}_{2}$ for $2 \mathrm{~h}$, the cells that adhered to the bottom of the culture dish were identified as PBMCs.

Cells. THP-1 cells (Type Culture Collection of the Chinese Academy of Sciences, Shanghai, China) were cultured in RPMI-1640 complete medium (cat. no. 11875093; Thermo Fisher Scientific, Inc.) supplemented with $10 \%$ fetal bovine serum (cat. no. SH30084.03; Hyclone; Thermo Fisher Scientific, Inc.) at $37^{\circ} \mathrm{C}$ and $5 \% \mathrm{CO}_{2}$ for $48 \mathrm{~h}$. The cells were treated with $1 \mu \mathrm{g} / \mathrm{ml}$ lipopolysaccharide (LPS) for $24 \mathrm{~h}$ to simulate a sepsis environment (14) and then compared with THP-1 cells that were not treated with LPS. The expression of miR-365 and IL-6 in the cells was measured.

Reverse transcription-quantitative polymerase chain reaction (RT-qPCR). Total RNA was extracted from $100 \mu \mathrm{l}$ blood or $2 \times 10^{6}$ PBMCs $\left(2 \times 10^{7} / \mathrm{ml}\right)$ using TRIzol reagent (Thermo Fisher Scientific, Inc.) following the manufacturer's protocol (15). The same procedure was used as for patient samples. The concentration and quality of the RNA was measured using a Nanodrop ND2000 ultraviolet spectrophotometer (Thermo Fisher Scientific, Inc., Wilmington, DE, USA). Subsequently, complementary DNA was obtained by RT from $1 \mu \mathrm{g}$ RNA and stored at $-20^{\circ} \mathrm{C}$. RT of mRNA was performed using a TIANScript II cDNA First Strand Synthesis kit, and RT of miRNA was performed using an miRcute miRNA cDNA First Strand Synthesis kit (both Tiangen Biotech Co., Ltd., Beijing, China) according to the manufacturers protocol.

PCR was performed using a SuperReal PreMix (SYBR Green) RT-qPCR kit (Tiangen Biotech Co., Ltd.) to detect mRNA expression of IL-6; GAPDH was used as an internal reference. The PCR primer sequences used were as follows: IL-6 forward, 5'-GGCACTGGCAGAAAACAACC-3' and reverse, 5'-GCAAGTCTCCTCATTGAATCC-3'; and GAPDH forward, 5'-GGGAAACTGCGGCGTGAT-3' and reverse, 5'-AAAGGTGGAGGAGTGGGT-3'. The reaction system $(25 \mu \mathrm{l})$ was composed of $12.5 \mu \mathrm{l}$ SYBR Premix EXTaq, $0.5 \mu \mathrm{l}$ upstream primer, $0.5 \mu \mathrm{l}$ downstream primer, $1 \mu \mathrm{l} \mathrm{cDNA}$ and $10.5 \mu \mathrm{l}$ double distilled (dd) $\mathrm{H}_{2} \mathrm{O}$. The PCR conditions were an initial denaturation at $95^{\circ} \mathrm{C}$ for $30 \mathrm{sec}$, followed by 45 cycles of denaturation at $95^{\circ} \mathrm{C}$ for $5 \mathrm{sec}$ and annealing at $57^{\circ} \mathrm{C}$ for $30 \mathrm{sec}$; with final extension at $72^{\circ} \mathrm{C}$ for $1 \mathrm{~min}$ (iQ5 Multicolor Real-Time PCR Detection System; Bio-Rad Laboratories, Inc., Hercules, CA, USA). The $2^{-\Delta \Delta \mathrm{Cq}}$ method (16) was used to calculate the relative expression of IL- 6 mRNA against GAPDH. Each sample had a minimum of three repeats.

The expression of miR-365 was determined using U6 as an internal reference. The PCR primer sequences used were as follows: miR-365 forward, 5'-GCGTAATGCCCCTAA AAATCC-3', the reverse primer was universal and provided by the kit. The forward and reverse PCR primer sequences used for U6 were 5'-AACGCTTCACGAATTTGCGT-3' and 5'-CTCGCTTCGGCAGCACA-3', respectively. The reaction system $(20 \mu \mathrm{l})$ contained $10 \mu \mathrm{l}$ RT-qPCR-Mix, $0.5 \mu \mathrm{l}$ upstream primer, $0.5 \mu \mathrm{l}$ downstream universal primer, $2 \mu \mathrm{l}$ cDNA and $7 \mu \mathrm{ldd} \mathrm{d}_{2} \mathrm{O}$. The reaction protocol was: Initial denaturation at $90^{\circ} \mathrm{C}$ for $30 \mathrm{sec} ; 40$ cycles of denaturation at $95^{\circ} \mathrm{C}$ for $5 \mathrm{sec}$ and annealing at $60^{\circ} \mathrm{C}$ for $34 \mathrm{sec}$; with final extension at $72^{\circ} \mathrm{C}$ for $1 \mathrm{~min}$. The $2^{-\Delta \Delta \mathrm{Cq}}$ method was used to calculate the relative expression of miR-365 against U6. Each sample had a minimum of three repeats.

Western blot analysis. A precooled radio-immunoprecipitation assay lysis buffer $(600 \mu \mathrm{l})$ composed of $50 \mathrm{mM}$ Tris-base, $1 \mathrm{mM}$ EDTA, $150 \mathrm{mM} \mathrm{NaCl}, 0.1 \%$ sodium dodecyl sulfate, $1 \%$ Triton-X-100 and 1\% sodium deoxycholate (all Beyotime Institute of Biotechnology) was used to lyse the samples (100 $\mu \mathrm{l}$ blood or $2 \times 10^{6}$ cells). Following lysis for $50 \mathrm{~min}$ on ice, the mixture was centrifuged at $12,000 \mathrm{x}$ g at $4^{\circ} \mathrm{C}$ for $5 \mathrm{~min}$. The supernatant was used to determine the protein concentration using a bicinchoninic acid protein concentration determination kit [RTP7102, Real-Times (Beijing) Biotechnology Co., Ltd., Beijing, China]. Protein samples $(20 \mu \mathrm{g})$ were mixed with a sodium dodecyl sulfate loading buffer (cat. no. P0015; Beyotime, Institute of Biotechnology) prior to denaturation in a boiling water bath for $5 \mathrm{~min}$. The samples ( $20 \mu \mathrm{g} / \mathrm{lane}$ ) were then subjected to $10 \%$ SDS-PAGE gel electrophoresis. The resolved proteins were transferred to polyvinylidene difluoride membranes on ice (100 V, $2 \mathrm{~h}$ ) and blocked with 5\% skimmed milk at room temperature for $1 \mathrm{~h}$. The membranes were subsequently incubated with rabbit anti-human primary antibodies against IL-6 (1:1,000; ab6672) or $\beta$-actin (1:5,000; ab129348; both Abcam, Cambridge, UK) at $4^{\circ} \mathrm{C}$ overnight. Following washing with PBS with Tween-20 three times for $15 \mathrm{~min}$, the membranes were incubated with goat anti-rabbit horseradish peroxidase-conjugated secondary antibody $(1: 3,000$; ab6721; Abcam) for $1 \mathrm{~h}$ at room temperature. Following this they were washed again with PBS with Tween-20 three times for $15 \mathrm{~min}$. The membranes were then developed using an ECL Western Blotting Substrate kit (ab65623; Abcam) for imaging. Image Lab version 3.0 software (Bio-Rad Laboratories, Inc.) was used to acquire and analyze the imaging signals. The relative content of IL- 6 protein was expressed as the IL- $6 / \beta$-actin ratio. 

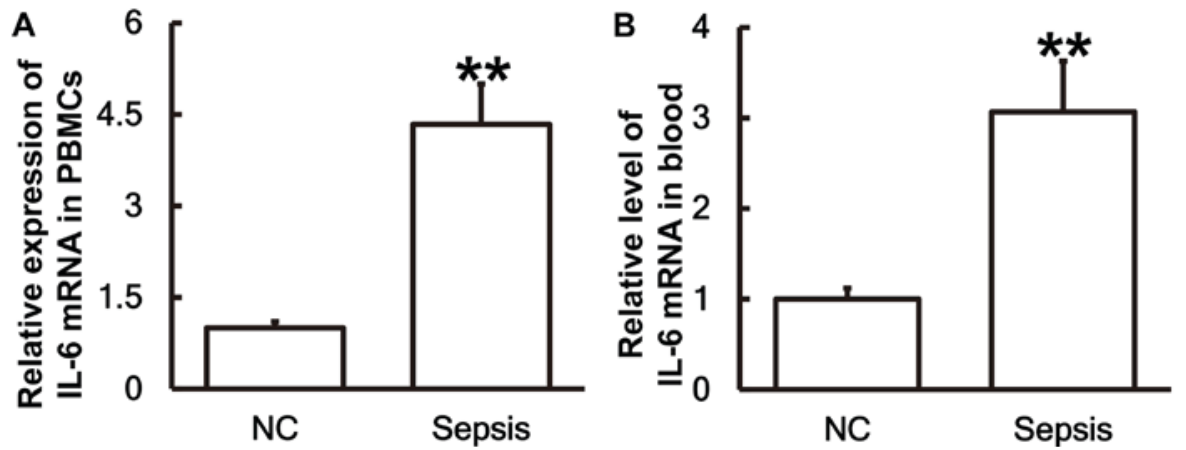

Figure 1. Patients with sepsis exhibit significantly higher levels of IL-6 mRNA compared with the NC group. IL-6 mRNA expression in (A) PBMCs and (B) blood was measured using reverse transcription-quantitative polymerase chain reaction. ${ }^{* *} \mathrm{P}<0.01$ vs. the NC group. IL, interleukin; $\mathrm{NC}$, negative control; PBMC, peripheral blood mononuclear cell.

A
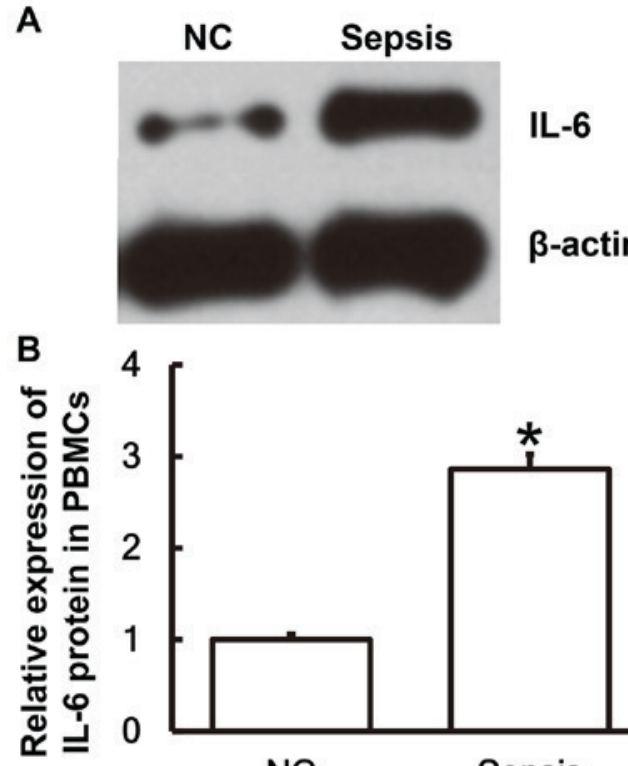

(1.
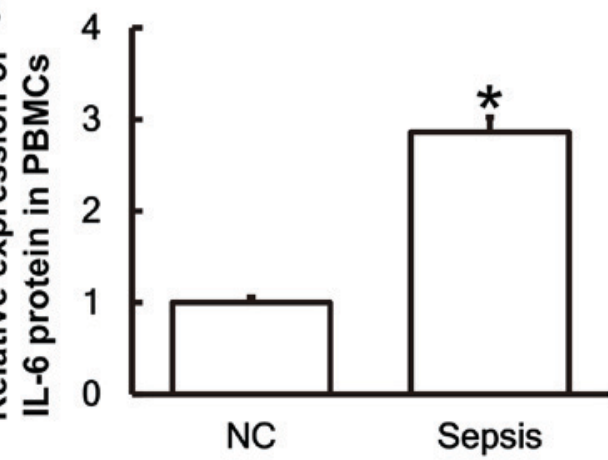

Figure 2. IL-6 protein expression is significantly higher in PBMCs from patients with sepsis following multiple trauma compared with the $\mathrm{NC}$ group. (A) Western blot analysis was performed to measure the protein expression of IL-6 in PBMCs. (B) This was then quantified using Image Lab version 3.0 software. ${ }^{*} \mathrm{P}<0.05$ vs. the $\mathrm{NC}$ group. IL, interleukin; NC, negative control; PBMC, peripheral blood mononuclear cell.

ELISA. Serum levels of IL-6 were tested using a human IL-6 ELISA kit (ab178013; Abcam) according to the manufacturer's protocol. In 96-well microplates, $50 \mu 1$ samples (10 $\mu$ l sample liquid and $40 \mu 1$ diluent) and blank (diluent) were set into predefined wells. Horseradish peroxidase-labelled conjugates $(100 \mu \mathrm{l})$ were added to all wells prior to sealing the plates for incubation at $37^{\circ} \mathrm{C}$ for $1 \mathrm{~h}$. Following washing of the plates five times with washing liquid provided by the kit, substrates $\mathrm{A}$ (50 $\mu \mathrm{l})$ and $\mathrm{B}(50 \mu \mathrm{l}$; provided by the kit) were added into each well. Following incubation at $37^{\circ} \mathrm{C}$ for $15 \mathrm{~min}$, a stop solution (50 $\mu \mathrm{l})$ was added into each well, and the absorbance of each well was measured at $450 \mathrm{~nm}$ within $15 \mathrm{~min}$.

Dual luciferase reporter assay. Bioinformatics prediction is a powerful tool for the study of the functions of miRNAs. To understand the regulatory mechanism of IL-6, several different bioinformatics tools were used to predict miRNA

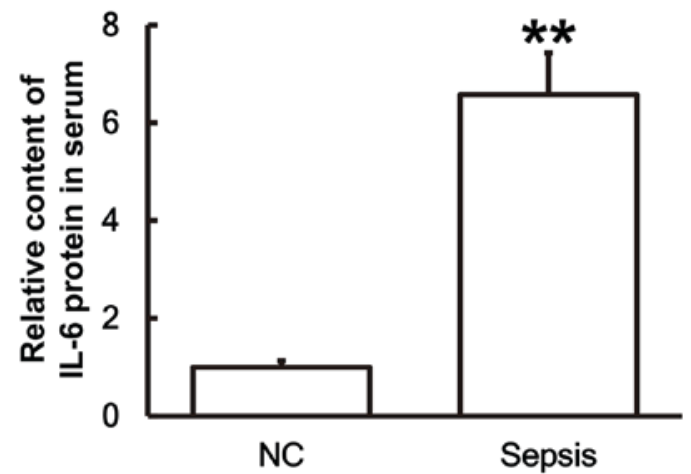

Figure 3. IL-6 protein levels in the serum of patients with sepsis are significantly higher than in the NC group. ELISA was used to measure the protein content of IL-6 in serum for patients with sepsis and the NC group. ${ }^{* * *} \mathrm{P}<0.01$ vs. the NC group. NC, negative control; IL, interleukin.

molecules that may regulate IL-6. These included miRanda (microrna.org/microrna/home.do), TargetScan (targetscan.org), PiTa (genie.weizmann.ac.il/pubs/mir07/mir07_data.html), RNAhybrid (bibiserv.techfak.uni-bielefeld.de/rnahybrid/) and PicTar (pictar.mdc-berlin.de). Wild-type (WT) and mutant seed regions of miR-365 in the 3'-untranslated region (UTR) of the IL-6 gene were chemically synthesized in vitro, Spe-1 and HindIII restriction sites were added, and then cloned into pMIR-REPORT luciferase reporter plasmids (Ambion; Thermo Fisher Scientific, Inc.). Plasmids $(0.8 \mu \mathrm{g})$ with WT or mutant 3'-UTR DNA sequences were co-transfected with agomiR-365 (100 nM; Sangon Biotech Co., Ltd., Shanghai, China) into 293 T cells (Type Culture Collection of the Chinese Academy of Sciences). Following cultivation for $24 \mathrm{~h}$ the cells were lysed using Dual-luciferase Reporter Assay System (Promega Corporation, Madison, WI, USA) according to the manufacturer's protocol, and the fluorescence intensity was measured using a GloMax 20/20 luminometer (Promega Corporation). Using Renilla fluorescence activity as the internal reference, the fluorescence values of each group of cells were measured.

Statistical analysis. The results were analyzed using SPSS version 18.0 statistical software (SPSS, Inc., Chicago, IL, USA). The results are expressed as the mean \pm standard deviation. Data were tested for normality. Multigroup measurement data were analyzed using one-way analysis of variance. In case 

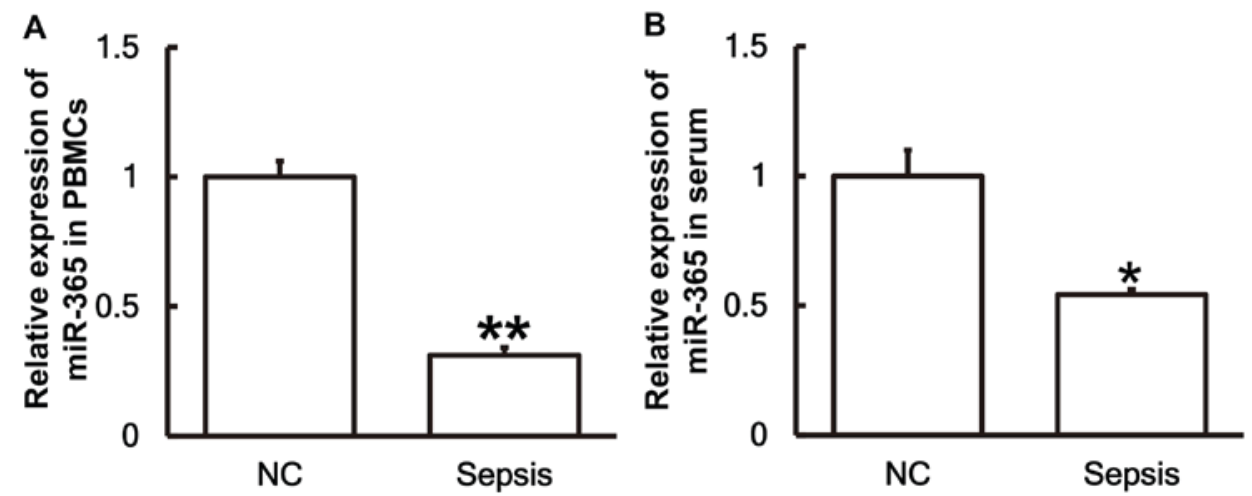

Figure 4. Expression of miR-365 is significantly lower in patients with sepsis compared with the NC group. The expression of miR-365 in (A) PBMCs and (B) serum of patients with sepsis and the $\mathrm{NC}$ group were measured using reverse transcription-quantitative polymerase chain reaction. " $\mathrm{P}<0.05$ and ${ }^{* *} \mathrm{P}<0.01$ vs. the NC group. miR, microRNA; NC, negative control; PBMC, peripheral blood mononuclear cells.

of homogeneity of variance, least significant difference and Student-Newman-Keuls methods were used; in case of heterogeneity of variance, Tamhane's T2 or Dunnett's T3 method was used. $\mathrm{P}<0.05$ was considered to indicate a statistically significant difference.

\section{Results}

Patients with sepsis following multiple traumas exhibit higher IL-6 mRNA levels than patients without sepsis. To measure the expression of IL-6 mRNA in different samples, RT-qPCR was performed. The results demonstrated that the levels of IL-6 mRNA in PBMCs (Fig. 1A) and blood (Fig. 1B) from patients with sepsis were significantly higher than those in the control group $(\mathrm{P}<0.01)$.

IL-6 protein expression in PBMCs is upregulated in patients with sepsis following multiple trauma. To determine the expression of the IL-6 protein in PBMCs, western blot analysis was performed. The results revealed that IL-6 protein expression in PBMCs from patients with sepsis was significantly elevated compared with the NC group ( $\mathrm{P}<0.05$; Fig. $2 \mathrm{~A}$ and $\mathrm{B})$.

Serum from patients with sepsis following multiple trauma contains a higher IL-6 content compared with serum from patients without sepsis. To examine the secretion of IL-6 by PBMCs, ELISA was performed. The results demonstrated that the IL-6 content in the serum of patients with sepsis was significantly higher than in the control group $(\mathrm{P}<0.01$; Fig. 3$)$.

Patients with sepsis following multiple trauma exhibit lower levels of miR-365 than patients without sepsis. To investigate the levels of miR-365 in the serum and PBMCs, RT-qPCR was performed. The results revealed that the levels of miR-365 in PBMCs (Fig. 4A) and serum (Fig. 4B) from patients with sepsis were significantly lower than those in the control group $(\mathrm{P}<0.01$ and $\mathrm{P}<0.05$, respectively).

IL-6 expression is upregulated whereas miR-365 expression is downregulated in THP-1 cells stimulated with LPS. To simulate sepsis at a cellular level THP-1 cells were treated with LPS for $24 \mathrm{~h}$ prior to the levels of miR-365 and IL- 6 being measured. The results revealed that IL-6 mRNA (Fig. 5A) and protein expression (Fig. 5B) in THP-1 cells treated with LPS were significantly higher than those in the NC group $(\mathrm{P}<0.05$ and $\mathrm{P}<0.01$, respectively). Conversely, the miR-365 expression in cells treated with LPS was significantly lower than the negative control group $(\mathrm{P}<0.01$; Fig. $5 \mathrm{C})$. The results suggest that IL-6 expression is upregulated and miR-365 expression is downregulated in THP-1 cells stimulated with LPS.

miR-365 binds with the 3'-UTR seed region of IL-6 mRNA to regulate its expression. To identify interactions between miR-365 and the 3'-UTR of IL-6 mRNA, a dual luciferase reporter assay was performed. Bioinformatics results identified that miR-365 was potentially able to regulate IL-6 (Fig. 6A). The fluorescence value of cells co-transfected with miR-365 mimics and WT luciferase reporter plasmids was significantly lower than that in the $\mathrm{NC}$ group $(\mathrm{P}<0.01)$. By contrast, the fluorescence value of cells co-transfected with miR-365 mimics and mutant luciferase reporter plasmids was not significantly different from that in the NC group (Fig. 6B). These results indicates that miR-365 binds with the 3'-UTR seed region of IL-6 mRNA to regulate its expression.

\section{Discussion}

Sepsis is a systemic inflammatory response syndrome caused by infection, which can lead to acute organ dysfunction or septic shock (17). In clinical practice, septic shock caused by sepsis is the most common cause of mortality in intensive care patients, and the mortality rate is $20-80 \%$ (18). Previous studies have demonstrated that cytokines serve key roles in the pathophysiology of post-traumatic sepsis, and the upregulation of tumor necrosis factor (TNF)- $\alpha$, IL- 6 and IL- 8 have been identified as associated with post traumatic infection $(19,20)$. IL-6 is a pleiotropic cytokine synthesized by mononuclear cells, macrophages, T cells, B cells, vascular endothelial cells and fibroblasts in response to IL-1 and TNF- $\alpha$ (21). Under normal circumstances, IL- 6 contents in the blood, serum and body are minimal, but it has a high biological activity and exerts an effect via paracrine and autocrine signaling pathways (22). IL-6 induces the production of C-reactive protein and fibrinogen in inflammation and promotes thrombosis (23). Increased levels of IL-6 in the body can cause inflammatory diseases by binding to the IL-6 receptor (24). 
A
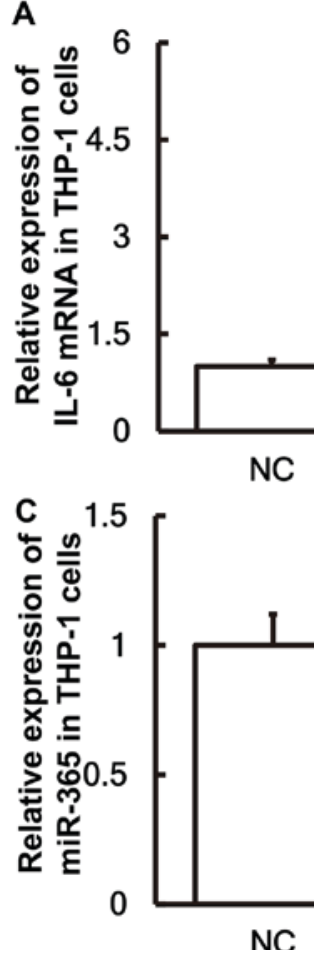

B
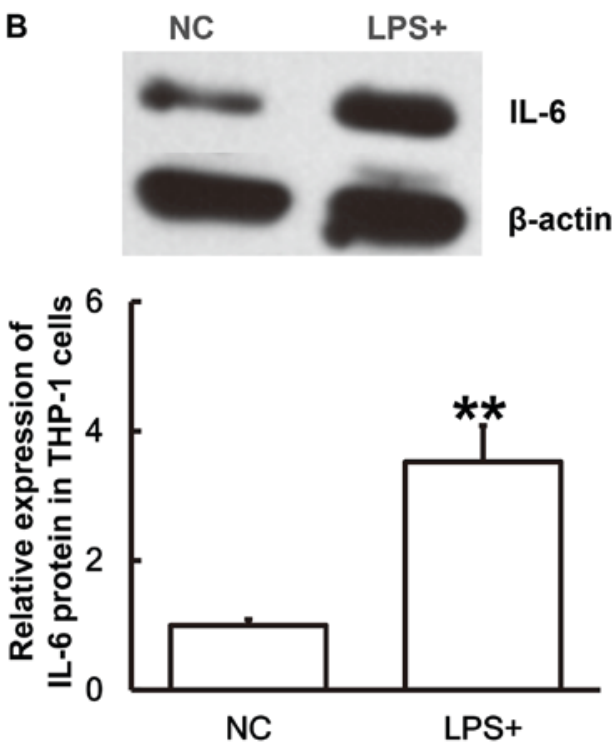

Figure 5. Expression levels of IL-6 and miR-365 in THP-1 cells. To replicate a sepsis environment at a cellular level, THP-1 cells were treated with LPS for $24 \mathrm{~h}$. Then the levels of (A) IL-6 mRNA, (B) IL-6 protein and (C) miR-365 in THP-1 cells was measured. Western blot analysis was used to measure the protein expression and reverse transcription-quantitative polymerase chain reaction was used to measure the mRNA and miR levels. ${ }^{*} \mathrm{P}<0.05$ and ${ }^{* *} \mathrm{P}<0.01 \mathrm{vs}$. the $\mathrm{NC}$ group. IL, interleukin; miR, microRNA; LPS, lipopolysaccharide; NC, negative control.

\section{A}

3' uauucCUAAAAAUCCCCGUAAu 5' hsa-miR-365

\section{| | || | |||||||}

\section{6:5' unguugUUGUUAAUgGGCAUUc 3' IL-6}

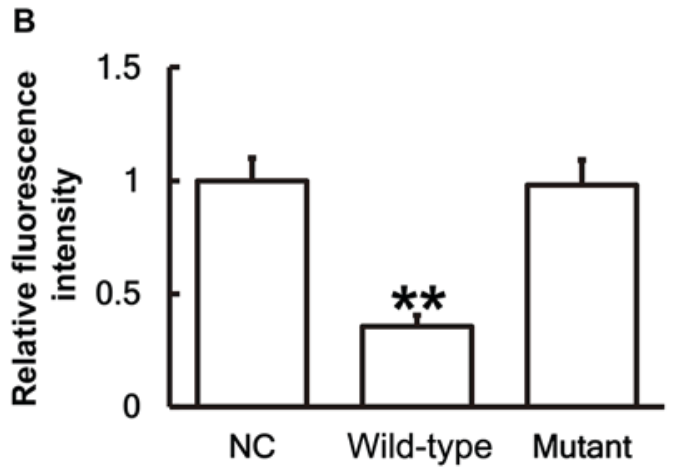

Figure 6. There are direct interactions between miR-365 and IL-6. (A) miR-365 was potentially able to regulate IL-6 through direct interactions. miR, microRNA; IL, interleukin. (B) Plasmids $(0.8 \mu \mathrm{g})$ with WT or mutant 3'-untranslated region DNA sequences were co-transfected with miR-365 mimics into 293T cells. Following cultivation for $24 \mathrm{~h}$ the cells were lysed using a dual luciferase reporter assay kit, and fluorescence intensity was measured. Using Renilla fluorescence activity as internal reference, the fluorescence values of each group of cells were measured. ${ }^{* *} \mathrm{P}<0.01$ vs. the NC group. IL, interleukin; miR, microRNA; WT, wild-type.

The IL-6 receptor is primarily expressed on the surface of liver cells, neutrophils, macrophages or lymphocytes. In rheumatoid arthritis IL-6 stimulates the secretion of inflammatory mediators by $\mathrm{T}$ lymphocytes and $\mathrm{B}$ lymphocytes, and promotes the maturation and differentiation of B lymphocytes (25). In inflammatory responses IL-6 is chemotactic to other inflammatory cells, including neutrophils and mononuclear macrophages (26). Riedemann et al (27) previously reported that IL-6 enhances the proinflammatory activity of secondary inflammatory mediator complement component $5 \mathrm{a}$. Pritts et al (28) previously reported that nuclear factor- $\kappa \mathrm{B}$ and activator protein-1 are associated with the regulation of IL-6 gene activation and synthesis in effector cells. In the present study, it was identified that IL-6 mRNA and protein expression are elevated in PBMCs and serum from patients with sepsis following multiple trauma, which suggests that septic infection following multiple trauma may activate mononuclear cells and lymphocytes, which secrete abundant IL-6 to produce a large number of antigen immune responses.

miRNA is widely associated with various pathophysiological processes, including the proliferation, invasion and migration of tumor cells, hypertension, diabetes mellitus and atherosclerosis $(29,30)$. It has been reported that the expression of miR-365 in breast cancer and endometriosis tissues is disordered (31). In NIH3T3 cells, ultraviolet irradiation significantly increases the expression of miR-365, which suggests that miR-365 has certain anti-tumor effects (32). Overexpression of tumor-suppressor gene NGX6 leads to the decreased expression of miR-365, suggesting that miR-365 may also have oncogene activity (33). The expression of miR-365 is downregulated in senescent lung fibroblasts, which indicates that miR-365 may be associated with the regulation of cell proliferation (34). In addition, miR-365 has negative regulation on IL-6 expression in 293 and HeLa cells (13). In the present study it has been identified that miR-365 is downregulated and 
IL-6 is upregulated in PBMCs and serum from patients with sepsis following multiple trauma. These results reveal that the levels of miR-365 and IL-6 in the serum reflect inflammatory responses and tissue injuries. In addition, THP-1 cells treated with LPS to simulate a sepsis environment achieved similar results. The dual luciferase reporter assay demonstrated that IL-6 is a direct target gene of miR-365.

In conclusion, the present study demonstrates that increased expression of IL-6 in patients with sepsis following multiple trauma is caused by decreased expression of miR-365. In addition, miR-365 may regulate the occurrence and immune response of sepsis following multiple trauma via IL-6. These results may elucidate agents for clinical diagnosis and treatment of the disease.

\section{Acknowledgements}

The authors would like to thank Dr Zhongwei Huang of Department of Emergency Surgery, Affiliated Hospital of Nantong University (Nantong, China) for his kind assistance.

\section{Funding}

No funding was received.

\section{Availability of data and materials}

The datasets used and/or analyzed during the current study are available from the corresponding author on reasonable request.

\section{Authors' contributions}

DZ conceived and designed the present study. HG performed the experiments and wrote the manuscript. XS and JX collected the samples. All authors collaborated to interpret results and develop the manuscript. The final version of the manuscript has been read and approved by all authors, and each author believes that the manuscript represents honest work.

\section{Ethics approval and consent to participate}

The Ethics Committee of Nantong University approved all procedures and written informed consent was obtained from all patients or their families prior to their inclusion in the present study.

\section{Patient consent for publication}

Patients provided consent for publication.

\section{Competing interests}

The authors declare that they have no competing interests.

\section{References}

1. Hilbert-Carius P, Wurmb T, Lier H, Fischer M, Helm M Lott C, Böttiger BW and Bernhard M: Care for severely injured persons: Update of the 2016 S3 guideline for the treatment of polytrauma and the severely injured. Anaesthesist 66: 195-206, 2017 (In German).
2. Kaukonen KM, Bailey M, Pilcher D, Cooper DJ and Bellomo R: Systemic inflammatory response syndrome criteria in defining severe sepsis. N Engl J Med 372: 1629-1638, 2015.

3. Jensen KO, Held L, Kraus A, Hildebrand F, Mommsen P, Mica L, Wanner GA, Steiger P, Moos RM, Simmen HP and Sprengel K: The impact of mild induced hypothermia on the rate of transfusion and the mortality in severely injured patients: A retrospective multi-centre study. Eur J Med Res 21: 37, 2016.

4. Lu Y, Yang Y, He X, Dong S, Wang W, Wang D and Zhang P: Esmolol reduces apoptosis and inflammation in early sepsis rats with abdominal infection. Am J Emerg Med 35: 1480-1484, 2017.

5. Patrick AL, Grin PM, Kraus N, Gold M, Berardocco M, Liaw PC and Fox-Robichaud AE; Canadian Critical Care Translational Biology Group: Resuscitation fluid composition affects hepatic inflammation in a murine model of early sepsis. Intensive Care Med Exp 5: 5, 2017.

6. Martin JB and Badeaux JE: Interpreting laboratory tests in infection: Making sense of biomarkers in sepsis and systemic inflammatory response syndrome for intensive care unit patients. Crit Care Nurs Clin North Am 29: 119-130, 2017.

7. American College of Chest Physicians/Society of Critical Care Medicine Consensus Conference: Definitions for sepsis and organ failure and guidelines for the use of innovative therapies in sepsis. Crit Care Med 20: 864-874, 1992.

8. Warren HS: Strategies for the treatment of sepsis. N Engl J Med 336: 952-953, 1997.

9. Huang M, Yang D, Xiang $M$ and Wang J: Role of interleukin-6 in regulation of immune responses to remodeling after myocardial infarction. Heart Fail Rev 20: 25-38, 2015.

10. Vila N, Reverter JC, Yague J and Chamorro A: Interaction between interleukin- 6 and the natural anticoagulant system in acute stroke. J Interferon Cytokine Res 20: 325-329, 2000.

11. Tezono K, Sarker KP, Kikuchi H, Nasu M, Kitajima I and Maruyama I: Bioactivity of the vascular endothelial growth factor trapped in fibrin clots: Production of IL-6 and IL-8 in monocytes by fibrin clots. Haemostasis 31: 71-79, 2001.

12. Anderson AE, Pratt AG, Sedhom MA, Doran JP, Routledge C, Hargreaves B, Brown PM, Lê Cao KA, Isaacs JD and Thomas R: IL-6-driven STAT signalling in circulating CD4+ lymphocytes is a marker for early anticitrullinated peptide antibody-negative rheumatoid arthritis. Ann Rheum Dis 75: 466-473, 2016.

13. Xu Z, Xiao SB, Xu P, Xie Q, Cao L, Wang D, Luo R, Zhong Y, Chen HC and Fang LR: miR-365, a novel negative regulator of interleukin-6 gene expression, is cooperatively regulated by $\mathrm{Sp} 1$ and NF-kappaB. J Biol Chem 286: 21401-21412, 2011.

14. Rump K, Brendt P, Frey UH, Schäfer ST, Siffert W, Peters J and Adamzik M: Aquaporin 1 and 5 expression evoked by the $\beta 2$ adrenoreceptor agonist terbutaline and lipopolysaccharide in mice and in the human monocytic cell line THP-1 is differentially regulated. Shock 40: 430-436, 2013.

15. Rio DC, Ares M Jr, Hannon GJ and Nilsen TW: Purification of RNA using TRIzol (TRI reagent). Cold Spring Harb Protoc 2010: pdb.prot5439, 2010.

16. Livak KJ and Schmittgen TD: Analysis of relative gene expression data using real-time quantitative PCR and the 2(-Delta Delta C(T)) method. Methods 25: 402-408, 2001.

17. Dellinger RP, Levy MM, Rhodes A, Annane D, Gerlach H, Opal SM, Sevransky JE, Sprung CL, Douglas IS, Jaeschke R, et al: Surviving sepsis campaign: International guidelines for management of severe sepsis and septic shock, 2012. Intensive Care Med 39: 165-228, 2013.

18. Heumann D, Glauser MP and Calandra T: Molecular basis of host-pathogen interaction in septic shock. Curr Opin Microbiol 1: 49-55, 1998.

19. Wang J and Li C: Systemic inflammatory response syndrome, compensatory anti-inflammatory response syndrome and multiple organ dysfunction syndrome. Chin J Crit Care Med: 38-40, 2003.

20. Mimasaka S, Hashiyada M,Nata M and Funayama M: Correlation between serum IL-6 levels and death: Usefulness in diagnosis of 'traumatic shock'? Tohoku J Exp Med 193: 319-324, 2001.

21. DeLong WG Jr and Born CT: Cytokines in patients with polytrauma. Clin Orthop Relat Res: 57-65, 2004.

22. Stover JF, Sakowitz OW, Schoning B, Rupprecht S, Kroppenstedt SN, Thomale UW, Woiciechowsky C and Unterberg AW: Norepinephrine infusion increases interleukin-6 in plasma and cerebrospinal fluid of brain-injured rats. Med Sci Monit 9: BR382-BR388, 2003.

23. Baeuerle PA and Henkel T: Function and activation of NF-kappa $\mathrm{B}$ in the immune system. Annu Rev Immunol 12: 141-179, 1994. 
24. Tone M, Powell MJ, Tone Y, Thompson SA and Waldmann $\mathrm{H}$ : IL-10 gene expression is controlled by the transcription factors Sp1 and Sp3. J Immunol 165: 286-291, 2000.

25. Hu F, Liu H, Xu L, Li Y, Liu X, Shi L, Su Y, Qiu X, Zhang X Yang Y, et al: Hypoxia-inducible factor-1 $\alpha$ perpetuates synovial fibroblast interactions with $\mathrm{T}$ cells and $\mathrm{B}$ cells in rheumatoid arthritis. Eur J Immunol 46: 742-751, 2016.

26. Luo Q, Ma X, Wahl SM, Bieker JJ, Crossley M and Montaner LJ: Activation and repression of interleukin-12 p40 transcription by erythroid Kruppel-like factor in macrophages. J Biol Chem 279: 18451-18456, 2004.

27. Riedemann NC, Neff TA, Guo RF, Bernacki KD, Laudes IJ, Sarma JV, Lambris JD and Ward PA: Protective effects of IL-6 blockade in sepsis are linked to reduced C5a receptor expression. J Immunol 170: 503-507, 2003.

28. Pritts T, Hungness E, Wang Q, Robb B, Hershko D and Hasselgren PO: Mucosal and enterocyte IL-6 production during sepsis and endotoxemia-role of transcription factors and regulation by the stress response. Am J Surg 183: 372-383, 2002.

29. Varshney J and Subramanian S: MicroRNAs as potential target in human bone and soft tissue sarcoma therapeutics. Front Mol Biosci 2: 31, 2015.
30. Liz J and Esteller M: lncRNAs and microRNAs with a role in cancer development. Biochim Biophys Acta 1859: 169-176, 2016.

31. Ohlsson Teague EM, Van der Hoek KH, Van der Hoek MB, Perry N, Wagaarachchi P, Robertson SA, Print CG and Hull LM: MicroRNA-regulated pathways associated with endometriosis. Mol Endocrinol 23: 265-275, 2009.

32. Guo L, Huang ZX, Chen XW, Deng QK, Yan W, Zhou MJ, Ou CS and Ding ZH: Differential expression profiles of microRNAs in NIH3T3 cells in response to UVB irradiation. Photochem Photobiol 85: 765-773, 2009.

33. Wang XY, Wu MH, Liu F, Li Y, Li N, Li GY and Shen SR: Differential miRNA expression and their target genes between NGX6-positive and negative colon cancer cells. Mol Cell Biochem 345: 283-290, 2010.

34. Maes OC, Sarojini H and Wang E: Stepwise up-regulation of microRNA expression levels from replicating to reversible and irreversible growth arrest states in WI-38 human fibroblasts. J Cell Physiol 221: 109-119, 2009. 